\title{
Children are more forgiving of accidental harms across development
}

\author{
Dorsa Amir ${ }^{1}$, Richard E. Ahl ${ }^{1}$, W. Shelby Parsons ${ }^{1}$, Katherine McAuliffe ${ }^{1}$ \\ 1. Boston College, Department of Psychology, Chestnut Hill, MA 02467, USA
}

*Corresponding author: Dorsa Amir, dorsa.amir@bc.edu

The authors declare no competing interests.

This work was supported by the John Templeton Foundation (61138).

Open data \& analysis scripts are available at $\mathrm{DOI} 10.17605 / \mathrm{OSF} . \mathrm{IO} / \mathrm{M} 6 \mathrm{FHW}$ 


\begin{abstract}
:
Forgiveness is a powerful feature of human social life, allowing for the restoration of positive, cooperative relationships. Despite its importance, we know relatively little about how forgiveness develops in early life and the features that shape forgiveness decisions. Here, we investigate forgiveness behavior in children between the ages of 5 and $10(N=257)$ from the United States, varying transgressor intent and remorse in a behavioral task that pits punishment against forgiveness. We find that baseline levels of forgiveness are high, suggesting children assume the best of transgressors in the absence of information about intent and remorse. We also find age-related increases in sensitivity to intent, but not remorse, such that older children are more likely to forgive accidental transgressions. As forgiveness is an important tool in the human social toolkit, exploring the ways in which this ability develops across age can help us better understand the early roots of human cooperation.
\end{abstract}

Keywords: forgiveness, judgment, cooperation, social cognition, development, childhood

\title{
Research Highlights:
}

- Forgiveness is an important component of our social toolkit in the face of transgressions

- We know relatively little about the social inputs that shape forgiveness decisions in early life

- We measure the effects of transgressor intent and remorse against a baseline of no information

- We find that intent matters more than remorse in promoting forgiveness behavior across development 


\section{Introduction:}

Cooperation is a key feature of human social life, underpinning the vast networks found across human societies (Henrich et al., 2005). These cooperative interactions are not always harmonious, however, as transgressions can and do occur. Consequently, social behaviors such as punishment and forgiveness are crucial for the maintenance of cooperative relationships (Fehr \& Gächter, 2000; Forster et al., 2019). While much work has focused on punishment's role in restoring cooperation (Raihani et al., 2012), forgiveness - which has been broadly defined as a prosocial change toward a perceived transgressor (Forster et al., 2019) - can also restore positive relationships, in sometimes lower-cost ways. Indeed, when formally modeled, generous-tit-for-tat strategies that allow for the forgiveness of transgressions can invade and outcompete standard tit-for-tat strategies (Godfray, 1992), suggesting forgiveness can be a successful strategy in repeated interactions.

Advances in the adult literature have helped shape our understanding of the form and function of forgiveness (Godfray, 1992; McCullough, 2008; Worthington Jr. et al., 2018) as a cognitive system for resolving interpersonal conflict (McCullough et al., 2013). Functionally, forgiveness can be thought of as a set of motivational changes whereby an individual becomes less disposed to retaliation and more disposed to reconcile with the transgressor (McCullough et al., 1997). Additionally, our understanding of the psychological mechanisms supporting forgiveness has been refined through experimental and psychometric research with adults. For instance, work with adults suggests that decision-makers are sensitive to social information, tending to forgive more in cases where the transgressor is remorseful (Jeter \& Brannon, 2018; Tabak et al., 2012) or where the transgression is deemed accidental (Wohl \& Reeder, 2004). Further, psychometric work has helped elucidate the underlying psychological structure of forgiveness; in a recent study, Forster et al. (2019) found the best psychometric model of forgiveness is a single attitudinal dimension ranging from malevolence to benevolence - an approach used to develop the dependent variable in the current study.

Despite its importance to our social lives, we know surprisingly little about the emergence of forgiveness in early life (van der Wal et al., 2017). Developmental work into this topic can help elucidate the building blocks of this social ability and how they dissociate across ontogeny. A small but growing body of literature suggests that children's forgiveness becomes increasingly sophisticated with age (Darby \& Schlenker, 1982, 1989). When forming third-party judgments, there is evidence to suggest that children are sensitive to relevant social cues when making forgiveness decisions. For instance, in hypothetical vignettes, children report being more willing to forgive transgressions that are accidental (Nobes et al., 2017; Ohbuchi \& Sato, 1994) and low in severity (Goss, 2002). They are also more likely to 
report that they would forgive transgressors who are remorseful (Darby \& Schlenker, 1982, 1989; Vaish et al., 2011) and evaluate them more positively (Banerjee et al., 2010; Oostenbroek \& Vaish, 2019b; Smith et al., 2010). These judgments may, in part, be related to broader developments in theory-ofmind ability. For instance, children who pass a false belief task deem it less acceptable to punish accidental transgressions (Killen et al., 2011).

However, while the elicitation of vignette-based judgments is helpful for understanding how children reason about forgiveness, it is unclear how these judgments translate to first-person decisionmaking. This relationship between judgments and behavior is complicated by the knowledge-behavior gap in children - the dissociation between an individual's actual behavior and their judgments of normative behavior (Blake et al., 2014). For instance, in other tasks measuring social behavior, while children are aware of norms surrounding, say, fairness, they still choose to act selfishly and prefer not to share (Kogut, 2012; Smith et al., 2013). Thus, it may be the case that a closer examination of children's actual behavior may provide novel insights, above and beyond their reported forgiveness-related judgments. Consequently, of special interest are the few experimental studies that have examined children's forgiveness when they themselves are the targets of a transgression. These studies largely suggest that children are sensitive to transgressor remorse. In a study with 4-to-7 year-old American children, Smith and Harris (2012) find that when children are the victim of a transgression, they report feeling better and judge the transgressor to be nicer when an apology is issued Further, in a study with 6 and 7-year-old American children, Drell and Jaswal (2016) find that children are more willing to share resources - in this case, stickers - with a transgressor who offers an apology as opposed to one who does not. And more recently, in a study with 4 and 5-year-old American children, Oostenbroek and Vaish (2019a) find that children are more willing to reward a remorseful transgressor over an unremorseful one - in this case, by gifting them a cloth flower.

While past work highlights a role for remorse in guiding children's forgiveness, we are aware of no prior work that directly tests children's forgiveness as a result of a transgressor's intentions, in cases where participants themselves are the targets of a transgression. However, in research inspired by Piaget (1932), Cushman and colleagues (2013) demonstrate that between the ages of four and eight, American children increasingly make moral judgments on the basis of an actor's intent, as opposed to the outcome that the actor brings about. That is, they believe that accidental harms - bad outcomes with benign intent - are less "naughty" and less punishable than attempted harms — benign outcomes with bad intent. These results lead to the prediction that children will be more forgiving towards accidental transgressors across development. 
The studies above suggest that children incorporate relevant social information into their forgiveness behavior. However, we currently do not know whether children's firsthand forgiveness behavior is conditioned on whether a transgression is intentional or accidental, how information about intent interfaces with remorse, or the extent to which children forgive in the absence of this information, particularly in cases in which children themselves are victims of transgressions. Here, we examine how information about transgressor intent and remorse influences children's forgiveness behaviors in a behavioral task that allows a continuous choice between punishment and forgiveness.

\section{Methods:}

\subsection{Participants:}

Our participants were 257 U.S. American children between the ages of 5 and 10 years old $(\mathrm{M}=$ $7.85, \mathrm{SD}=1.72,125$ girls). We chose this age range in hopes of achieving high rates of comprehension in our task and to capture a period of life marked by increasing sophistication in children's understanding of moral responsibility, punishment, and distributive judgment (Shultz et al., 1986; Smith \& Warneken, 2016). An additional 14 children were tested but excluded based on pre-specified criteria: parental intervention in the study $(n=1)$, failure to follow directions $(n=1)$, parent asked to stop $(n=1)$, neurodevelopmental disorders $(n=2)$, experimenter error $(n=7)$, language comprehension issues $(n=1)$, and previous participation in the task $(n=1)$. The target sample size was determined by an a priori power analysis which, assuming a medium effect size $(\mathrm{d}=0.4)$ and $80 \%$ power, suggested a minimum sample size of 240 participants. In recruiting, we aimed for approximately 80 children in each of the three age groups - 5-6 year olds, 7-8 year olds, and 9-10 year olds - with the rule that no single age within each group should represent more than two-thirds of the participants therein. Our sample size exceeded the minimum sample size slightly in order to finish a weekend of testing at a given site.

Participants were recruited from a large city in the New England region of the United States, through institutional databases of interested families and in-person recruitment at local zoos, museums, and parks. Across testing locations, condition assignment and children's forgiveness behaviors were similar and did not significantly differ (see Supplement for more details). We also find no differences in age across conditions (see Supplement). The forgiveness task described below was sometimes followed by additional tasks measuring other social preferences. However; in all cases, the forgiveness task was first. Study methods were approved by the institutional review boards at the affiliated institution and adhere to international standards for ethical human subjects research. For all children, participation required written parental consent and children's verbal assent. Children older 
than seven also completed written assent forms. While individual demographic information was not collected for this study, information collected from subsequent studies among these same locations, similar times of year, and age groups breaks down to roughly $57 \%$ White, $13 \%$ Asian, $13 \%$ Other, $11 \%$ Black or African American, and 6\% Hispanic, withy $92 \%$ of parents holding a bachelor's degree or higher.

\subsection{Procedure:}

Across all conditions, the experimenter sat next to the participant and told them they would have the chance to make some drawings. The experimenter then introduced a novel resource: a "magic color scratch sheet". The sheet was a small, square piece of paper with a layer of black, carbon film on it that could be scratched off with a stylus, revealing rainbow colors underneath. The experimenter demonstrated the resource by drawing a star on one sheet. The participant was given a short period of time to practice drawing on the sheet. The experimenter then told the participant they would have a chance to make five more drawings and proceeded to bring out and open a small box that ostensibly held the additional sheets. However, upon opening the box, the experimenter "discovered" that the five sheets had already been drawn on. Experimenters were instructed to feign surprise and disappointment. The experimenter then said, "Oh no, it looks like someone before you already drew on them and you won't get to complete this activity. We don't have any more of these." While we did not directly measure children's own emotional reactions, previous work by Smith and Harris (2012) - using a similar protocol where promised resources were not delivered due to another child's actions suggest that children tend to be disappointed by this event.

Following this, the experimenter noticed and pulled out a note in the box which was allegedly from another experimenter. Here, to manipulate intent and remorse information, children were randomly assigned to one of five conditions in a $2 \times 2$ design with a baseline. The conditions were (1) a Baseline $(B)$ condition in which they were told "A kid that was here before drew on these scratch sheets.", (2) an Intentional / Remorse (IR) condition in which they were told "A kid that was here before you knew these were for you, but they drew on them anyway, on purpose. They are really sorry that they used the scratch sheets.", (3) an Intentional / No Remorse (INR) condition with the same information, except the "kid" is "not sorry that they used the scratch sheets,"(4) an Accidental / Remorse $(A R)$ condition, in which they were told "A kid that was here before you did not know these were for you, and they drew on them, accidentally. They are really sorry that they used the scratch sheets.", and (5) an Accidental / No Remorse (ANR) condition with the same information, except the 
"kid" is "not sorry." Following the exclusions outlined above, our final sample had $\mathrm{n}=55$ children in the Baseline condition, $\mathrm{n}=53$ in Accidental / Remorse, $\mathrm{n}=50$ in Accidental / No Remorse, $\mathrm{n}=50$ in Intentional / No Remorse and $\mathrm{n}=49$ children in the Intentional / Remorse condition.

Following the manipulation, the experimenter told the participant they had to decide what to do with the sheets. They could throw as many of the sheets as they wanted away into a trash can, or return as many of the sheets as they wanted to the child that drew them by placing them in an envelope. Note that children could not keep the sheets for themselves. We considered the number of sheets returned as a measure of forgiveness. The experimenter then asked the participant two comprehension questions to assess whether they understood how to throw away or return the drawings. Success rates for both comprehension questions were high $-90 \%$ and $96 \%$ of responses were spontaneously correct on the first try, respectively. If a participant's response was not spontaneously correct, the experimenter repeated the correct information, then asked the comprehension question again. This process was repeated once more. If the participant failed all three attempts, the researcher read the correct information to the child and moved on. We did not exclude on the basis of comprehension failures, in line with our a priori plan to not exclude such cases as children immediately receive the correct information before proceeding, but note that failure rates after three attempts on the two comprehension questions were quite low: $2 \%$ and $1 \%$, respectively.

Following the comprehension questions, the experimenter turned around to give the participant privacy. The participant was instructed to ring a bell when they were finished making their decision. Afterwards, the experimenter posed two recall questions, asking the participant to remember whether the transgression was intentional and whether the transgressor expressed remorse. Recall questions were not asked in the baseline condition. Recall rates were fairly high: $78 \%$ of participants accurately recalled whether the transgressor was intentional, and 90\% of participants accurately recalled whether the transgressor was remorseful. A generalized linear mixed model with subject-level random effects suggests that the recall rate for remorse is indeed higher than for intent (OR $=3.31,95 \%$ $\mathrm{Cl}[1.69,6.45], \mathrm{z}=3.5, \mathrm{p}<0.001)$. The results reported below include all participants, regardless of recall rate. However, to ensure that recall rates did not play a significant role in children's behaviors, we ran additional analyses (reported in the Supplement), and found that recall rates do not change the main findings reported below. The experimenter then asked the participant to judge how bad the transgressor's actions were. Please see the Supplement for our full protocol and visualizations of children's judgments. To ensure participants had a positive experience in the task, all children received prizes upon the study's conclusion. 
For each participant, we recorded the number of sheets given back to the transgressor (numeric, 0-5), the experimental condition (factor, five levels), and the age of the participant (numeric, calculated from date of birth). For nine participants with incomplete date-of-birth information, exact age was imputed as their reported age plus six months (e.g. if a parent reported their child's age as 8 , their exact age was recorded as 8.5 years). Data were coded from worksheets by an independent coder, and from videos of recorded sessions by a separate, independent coder. A comparison of video and paper coding for recorded sessions (approximately $88 \%$ of the sample) revealed high consistency, with a $93 \%$ match rate for the dependent variable of interest (number of sheets given back). In the small percentage of cases with coding conflict, a research assistant reviewed the live coding worksheet and video and reconciled the discrepancy, which was then reviewed again and approved by the senior experimenter.

We used $R$ version 4.0.0 for all analyses ( $R$ Core Team, 2020). A new variable for remorse was dummy coded ( $1=$ remorse, $0=$ no remorse) across the experimental conditions, as was a new variable for whether the transgression was accidental ( $1=$ accidental, $0=$ intentional). We ran a total of five Poisson regressions to investigate the role of intent (numeric, dummy coded 0-1), remorse (numeric, dummy coded 0-1), and condition (factor, five levels) on the number of sheets children chose to return to the transgressor (numeric, $0-5$ ). We also included exact age (numeric) to investigate developmental trends and gender (factor, male or female) to allow comparison to previous work on gender differences in prosocial behavior (Benenson et al., 2019).

\section{Results}

We find no main effects of condition or an interaction between condition (factor, five levels) and age (numeric, continuous) on children's forgiveness behavior (see Supplement). Interestingly, we find that children return a sizable number of sheets to the transgressor in the baseline condition $(M=$ 3.76, $S D=1.39$ ), even in the absence of intent and remorse information. Indeed, across all conditions, children gave back more sheets $(M=3.47, S D=1.53)$ than predicted by chance, $t(256)=10.09, p<$ 0.0001 . Looking just at the Baseline condition, we further do not find that children's forgiveness behavior changes with age (see Supplement for model output).

Participants' judgments of the badness of the transgressor's actions track these forgiveness behaviors, as well. On a scale of 1 being "very, very good" to 6 being "very, very bad", participants judge transgressors in the baseline condition $(M=3.72, S D=1.19)$ similarly to how they do in the Accidental / Remorse condition $(M=3.88, S D=1.04)$, suggesting that they do not assume the worst of 
transgressors in the absence of clear reasons to do so. Participants' judgments of the badness of the transgessor's actions are significantly higher in the remaining three conditions: Intentional / Remorse $(M=4.19, S D=1.06)$, Accidental $/$ No Remorse $(M=4.55, S D=1.00)$, and Intentional $/$ No Remorse $(M=$ $4.72, S D=1.11)$. This suggests intentional harms and lack of remorse are relevant to children's attitudes, as well as their behaviors (see Supplement for analysis). We also find a significant effect of age, such that older children are less harsh in their evaluations of the transgressor $(B=-0.13, S E=0.04, p=$ 0.0009). We also find a relationship between judgments and number of sheets given back, such that the more negative the judgment, the fewer number of sheets children return to the transgressor $(B=-0.07$, $S E=0.03, p=0.02$ ).

To investigate the primary research question of the effects of intent and remorse on forgiveness, we continued our analyses on the four experimental conditions, excluding the baseline. As mentioned above, we dummy coded our conditions to distinguish between accidental and intentional conditions, and between remorseful and unremorseful conditions. We built a total of five models to investigate how intent and remorse influence children's forgiveness behaviors across age (Table 1), one to consider the main effects of the variables of interest, two models to investigate how intent and remorse information interacts with age to influence forgiveness behaviors, one to investigate the twoway interaction between intent and remorse, and another to consider the three-way interaction between intent, remorse, and age. We do not find evidence for a two-way interaction between intent and remorse [LRT, $\chi 2, p=0.63]$, nor a three-way interaction between age, intent, and remorse [LRT, $\chi^{2}$, $p=0.77]$. We find no interaction between age and remorse but do find evidence of an interaction between age and intent (Table 1), suggesting that older children are more forgiving of accidental transgressions than intentional transgressions (Figure 1). We find no evidence of gender differences.

To further break down the interaction between age and intent, we conducted a simple slopes analysis to compare how age predicts the number of sheets given back between intentional and accidental conditions. Using the interactions package (Long, 2019), we find that there is no significant effect of age on forgiveness behavior in cases of intentional harms $(\beta=-0.02, S E=0.03, p=0.56)$, but there is a significant effect of age on forgiveness behavior in cases of accidental harms $(\beta=0.08, S E=$ $0.03, p=0.01$ ). In other words, the interaction between age and intent is driven by children being more forgiving of accidental harms as they get older. 


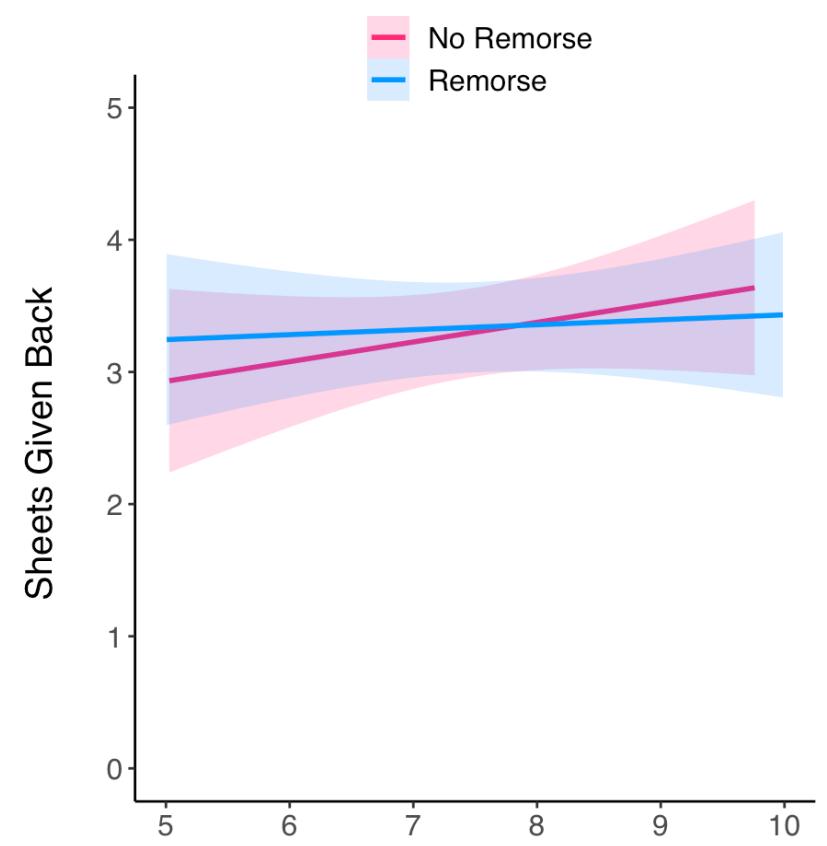

Age

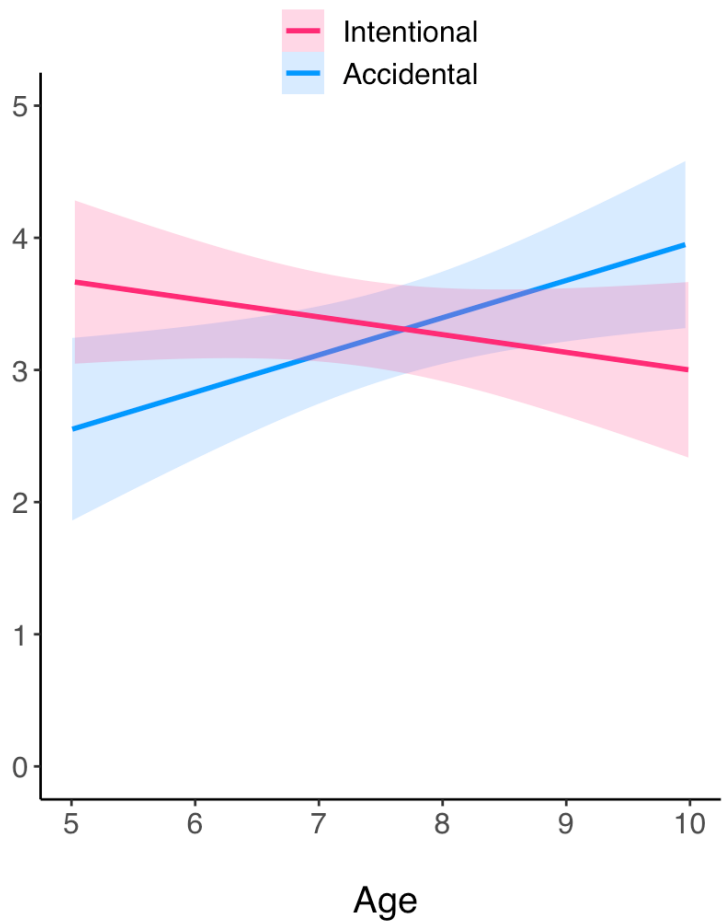

Age

Figure 1: Number of sheets given back by age and remorse (left) and intent (right) information. The shaded ribbons represent 95\% confidence intervals. 
Table 1: Effects and standard errors from Poisson regressions predicting number of sheets returned to the transgressor. Model 1 reports the main effects, Model 2 includes the exact age by remorse interaction, Model 3 includes an exact age by intent interaction, Model 4 includes the remorse by intent interaction, and Model 5 includes the three-way interaction between intent, remorse, and exact age. Table also shows goodness of fit.

\begin{tabular}{|c|c|c|c|c|c|}
\hline & Model 1 & Model 2 & Model 3 & $\begin{array}{l}\text { Model } \\
4\end{array}$ & Model 5 \\
\hline \multirow[t]{2}{*}{ (Intercept) } & $0.97^{* \star *}$ & $1.02^{* * *}$ & $1.40^{* * *}$ & $0.99^{* * *}$ & $1.49^{* * *}$ \\
\hline & $(0.20)$ & $(0.27)$ & $(0.26)$ & $(0.20)$ & $(0.37)$ \\
\hline \multirow[t]{2}{*}{ Exact Age } & 0.03 & 0.03 & -0.02 & 0.03 & -0.03 \\
\hline & $(0.02)$ & $(0.03)$ & $(0.03)$ & $(0.02)$ & $(0.05)$ \\
\hline \multirow[t]{2}{*}{ Accidental } & 0.00 & & $-0.81^{*}$ & -0.04 & -0.96 \\
\hline & $(0.08)$ & & $(0.37)$ & $(0.11)$ & $(0.54)$ \\
\hline \multirow[t]{2}{*}{ Remorseful } & 0.05 & -0.04 & & 0.01 & -0.17 \\
\hline & $(0.08)$ & $(0.37)$ & & $(0.11)$ & $(0.51)$ \\
\hline \multirow[t]{2}{*}{ Male } & -0.07 & -0.07 & -0.08 & -0.07 & -0.08 \\
\hline & $(0.08)$ & $(0.08)$ & $(0.08)$ & $(0.08)$ & $(0.08)$ \\
\hline \multirow[t]{2}{*}{ Exact Age * Remorseful } & & 0.01 & & & 0.02 \\
\hline & & $(0.05)$ & & & $(0.06)$ \\
\hline \multirow[t]{2}{*}{ Exact Age * Accidental } & & & $0.10^{*}$ & & 0.12 \\
\hline & & & $(0.05)$ & & $(0.07)$ \\
\hline \multirow[t]{2}{*}{ Remorseful * Accidental } & & & & 0.07 & 0.29 \\
\hline & & & & $(0.15)$ & $(0.74)$ \\
\hline \multirow{2}{*}{$\begin{array}{l}\text { Exact Age * Remorseful * } \\
\text { Accidental }\end{array}$} & & & & & -0.03 \\
\hline & & & & & $(0.09)$ \\
\hline AIC & 786.29 & 786.22 & 781.73 & 788.06 & 788.89 \\
\hline $\mathrm{BIC}$ & 802.83 & 802.77 & 798.27 & 807.91 & 818.67 \\
\hline Log Likelihood & -388.14 & -388.11 & -385.86 & -388.03 & -385.45 \\
\hline Deviance & 194.78 & 194.72 & 190.22 & 194.55 & 189.38 \\
\hline Num. obs. & 202 & 202 & 202 & 202 & 202 \\
\hline
\end{tabular}




\section{Discussion:}

Here, we examined how information about a transgressor's intent and remorse influences children's forgiveness in a task that pits forgiveness against punishment. In a large sample of American children, we find that in the absence of intent and remorse information, children are very forgiving, suggesting that they are filling in the blanks of the transgression rather charitably. While other work has found age-related increases in forgiveness across adolescence and adulthood (Cheng \& Yim, 2008; Girard \& Mullet, 1997), we did not find overall age-related increases in forgiveness across childhood, but do find that children's judgments of the transgressor soften with age, such that older children are less willing to say the transgressor's actions were "very, very bad". We further find targeted changes with age based on specific information about the transgressor, such that the transgressor's intent seems to matter relatively more across age, as children become increasingly forgiving of accidental harms. These results align with previous evidence suggesting older children view accidental harms as less punishable (Cushman et al., 2013).

Children's judgments of the transgressor's actions provide another interesting window into the emergence of forgiveness. We find that intentional harms and lack of remorse are judged more harshly, and that those who judged the transgressor more harshly are also less willing to return sheets to them. These results support the notion that children are reasoning about both remorse and intent in their evaluations, and aligns with previous work suggesting children's evaluations of others are often internally consistent with their behaviors (Paulus et al., 2018).

Our findings raise important questions that are ripe for exploration in future work. First, as previous work has suggested that theory-of-mind plays a role in shaping moral judgments of accidental versus intentional harms (Killen et al., 2011), it's possible that the age trends we observe are in part explained by proficiency in mentalizing ability. Thus, future work should consider more explicitly how theory-of-mind ability influences forgiveness decisions in similar contexts. Second, while we do not find a strong effect of remorse on children's forgiveness, this does not suggest that remorse plays no role, but rather that it may be weighted less when intent information is also available.

There are methodological differences between this study and others that could account for the limited role of remorse. For instance, in Oostenbroek \& Vaish (2019), children made a choice regarding which person to give a flower to: one who was remorseful or one who was not. This explicit contrast may have made the presence of an apology more salient. However, our results also differ from studies without these explicit contrasts; for instance, Drell and Jaswall (2016) find that children shared more with a transgressor that verbally apologized. Thus, it may be that remorse in our study was also less 
salient than in other studies where participants could actually see or hear a transgressor apologizing. While we find that children judge remorseful transgressors less harshly, this may not have been a strong enough manipulation to lead to behavioral differences. Differences in our findings compared to past work may also be due to variation in our measure, as our task involved a continuous decision between throwing away resources or returning them while other tasks frequently involve behaviors such as sharing or allocating resources across two characters. Our task also differed in that it asked children to distribute resources that were supposed to be for them but used by another individual. Further, our task involved first-person decisions, which may differ from past work examining thirdperson judgments. Taken together, however, our results do converge with previous findings in the literature suggesting that children's forgiveness behaviors become increasingly sensitive to relevant social cues, such as intent, across age. While apologies are generally thought to facilitate forgiveness, some work with adults has found that apologies actually decrease forgiveness following intentional harms (Struthers et al., 2008). This is not a pattern we observed in our age range. Further studies should thus explore this possibility in older children.

Overall, our findings suggest early-emerging limits to children's forgiveness of remorseful but intentional transgressors; such limits may have implications for forgiveness in adulthood. Given recent advances in our understanding of the psychological constructs (Forster et al., 2019) and neural mechanisms (Fourie et al., 2020) underpinning forgiveness, behavioral tasks like ours, in which recipients are the targets of transgressions and make a continuous choice between forgiveness and punishment regarding a single individual, may better represent how these social decisions are typically made in real settings. Given the importance of forgiveness in sustaining cooperative relationships, exploring the ways in which this ability develops across age, and the features that influence these behaviors, can help us better understand the early roots of human cooperation. 


\section{References}

Banerjee, R., Bennett, M., \& Luke, N. (2010). Children's reasoning about the self-presentational consequences of apologies and excuses following rule violations. The British Journal of Developmental Psychology, 28(Pt 4), 799-815. https://doi.org/10.1348/026151009x479475

Benenson, J. F., Durosky, A., Nguyen, J., Crawford, A., Gauthier, E., \& Dubé, É. (2019). Gender differences in egalitarian behavior and attitudes in early childhood. Developmental Science, 22(2), e12750. https://doi.org/10.1111/desc.12750

Blake, P. R., McAuliffe, K., \& Warneken, F. (2014). The developmental origins of fairness: The knowledge-behavior gap. Trends in Cognitive Sciences, 18(11), 559-561. https://doi.org/10.1016/j.tics.2014.08.003

Cushman, F., Sheketoff, R., Wharton, S., \& Carey, S. (2013). The development of intent-based moral judgment. Cognition, 127(1), 6-21. https://doi.org/10.1016/j.cognition.2012.11.008

Darby, B. W., \& Schlenker, B. R. (1982). Children's reactions to apologies. Journal of Personality and Social Psychology, 43(4), 742-753. https://doi.org/10.1037/0022-3514.43.4.742

Darby, B. W., \& Schlenker, B. R. (1989). Children's reactions to transgressions: Effects of the actor's apology, reputation and remorse. British Journal of Social Psychology, 28(4), 353-364.

Drell, M. B., \& Jaswal, V. K. (2016). Making amends: Children's expectations about and responses to apologies. Social Development, 25(4), 742-758.

Fehr, E., \& Gächter, S. (2000). Cooperation and punishment in public goods experiments. American Economic Review, 980-994.

Forster, D. E., Billingsley, J., Russell, V. M., McCauley, T. G., Smith, A., Burnette, J. L., Ohtsubo, Y., Schug, J., Lieberman, D., \& McCullough, M. E. (2019). Forgiveness takes place on an attitudinal continuum from hostility to friendliness: Toward a closer union of forgiveness theory and measurement. Journal of Personality and Social Psychology, No Pagination Specified-No 
Pagination Specified. https://doi.org/10.1037/pspioooo227

Fourie, M. M., Hortensius, R., \& Decety, J. (2020). Parsing the components of forgiveness: Psychological and neural mechanisms. Neuroscience \& Biobehavioral Reviews, 112, 437-451. https://doi.org/10.1016/j.neubiorev.2020.02.020

Godfray, H. C. (1992). The evolution of forgiveness. Nature, 355(6357), 206-207. https://doi.org/10.1038/355206ao

Goss, S. M. (2002). Interpersonal forgiveness in elementary school-aged children.

Henrich, J., Boyd, R., Bowles, S., Camerer, C., Fehr, E., Gintis, H., McElreath, R., Alvard, M., Barr, A., Ensminger, J., Henrich, N. S., Hill, K., Gil-White, F., Gurven, M., Marlowe, F. W., Patton, J. O., \& Tracer, D. (2005). "Economic man" in cross-cultural perspective: Behavioral experiments in 15 small-scale societies. Behavioral and Brain Sciences, 28(06). https://doi.org/10.1017/S0140525X05000142

Jeter, W. K., \& Brannon, L. A. (2018). 'I'll Make It Up to You:' Examining the effect of apologies on forgiveness. The Journal of Positive Psychology, 13(6), 597-604. https://doi.org/10.108o/17439760.2017.1291854

Killen, M., Mulvey, K. L., Richardson, C., Jampol, N., \& Woodward, A. (2011). The accidental transgressor: Morally-relevant theory of mind. Cognition, 119(2), 197-215. https://doi.org/10.1016/j.cognition.2011.01.006

Kogut, T. (2012). Knowing what I should, doing what I want: From selfishness to inequity aversion in young children's sharing behavior. Journal of Economic Psychology, 33(1), 226-236. https://doi.org/10.1016/j.joep.2011.10.003

Long, J. A. (2019). interactions: Comprehensive, User-Friendly Toolkit for Probing Interactions. https://cran.r-project.org/package=interactions

McCullough, M. E. (2008). Beyond revenge: The evolution of the forgiveness instinct. John Wiley \& Sons. 
McCullough, M. E., Kurzban, R., \& Tabak, B. A. (2013). Cognitive systems for revenge and forgiveness. Behavioral and Brain Sciences, 36(1), 1-15. https://doi.org/10.1017/S0140525X11002160

McCullough, M. E., Worthington Jr., E. L., \& Rachal, K. C. (1997). Interpersonal forgiving in close relationships. Journal of Personality and Social Psychology, 73(2), 321-336. https://doi.org/10.1037/0022-3514.73.2.321

Nobes, G., Panagiotaki, G., \& Engelhardt, P. E. (2017). The development of intention-based morality: The influence of intention salience and recency, negligence, and outcome on children's and adults' judgments. Developmental Psychology, 53(10), 1895-1911. https://doi.org/10.1037/devoooo38o

Ohbuchi, K.-I., \& Sato, K. (1994). Children's Reactions to Mitigating Accounts: Apologies, Excuses, and Intentionality of Harm. The Journal of Social Psychology, 134(1), 5-17. https://doi.org/10.1080/00224545.1994.9710877

Oostenbroek, J., \& Vaish, A. (2019a). The Emergence of Forgiveness in Young Children. Child Development, 9o(6), 1969-1986. https://doi.org/10.1111/cdev.13069

Oostenbroek, J., \& Vaish, A. (2019b). The benefits of forgiving: Young children respond positively to those who forgive. Journal of Experimental Psychology: General, 148(11), 1914-1924. https://doi.org/10.1037/xgeoooo576

Paulus, M., Nöth, A., \& Wörle, M. (2018). Preschoolers' resource allocations align with their normative judgments. Journal of Experimental Child Psychology, 175, 117-126. https://doi.org/10.1016/j.jecp.2018.05.001

Piaget, J. (1932). The moral judgment of the child. (pp. ix, 418). Harcourt, Brace.

R Core Team. (2020). R: A Language and Environment for Statistical Computing. R Foundation for Statistical Computing.

Raihani, N. J., Thornton, A., \& Bshary, R. (2012). Punishment and cooperation in nature. Trends in 
Ecology \& Evolution, 27(5), 288-295. https://doi.org/10.1016/j.tree.2011.12.004

Shultz, T. R., Wright, K., \& Schleifer, M. (1986). Assignment of Moral Responsibility and Punishment. Child Development, 57(1), 177-184. JSTOR. https://doi.org/10.2307/1130649

Smith, C. E., Blake, P. R., \& Harris, P. L. (2013). I should but I won't: Why young children endorse norms of fair sharing but do not follow them. PloS One, 8(3).

Smith, C. E., Chen, D., \& Harris, P. L. (2010). When the happy victimizer says sorry: Children's understanding of apology and emotion. British Journal of Developmental Psychology, 28(4), 727746.

Smith, C. E., \& Harris, P. L. (2012). He didn't want me to feel sad: Children's reactions to disappointment and apology. Social Development, 21(2), 215-228.

Smith, C. E., \& Warneken, F. (2016). Children's Reasoning about Distributive and Retributive Justice across Development. Developmental Psychology, 52(4), 613-628. https://doi.org/10.1037/a0040069

Struthers, C. W., Eaton, J., Santelli, A. G., Uchiyama, M., \& Shirvani, N. (2008). The effects of attributions of intent and apology on forgiveness: When saying sorry may not help the story. Journal of Experimental Social Psychology, 44(4), 983-992.

https://doi.org/10.1016/j.jesp.2008.02.006

Tabak, B. A., McCullough, M. E., Luna, L. R., Bono, G., \& Berry, J. W. (2012). Conciliatory Gestures Facilitate Forgiveness and Feelings of Friendship by Making Transgressors Appear More Agreeable. Journal of Personality, 8o(2), 503-536. https://doi.org/10.1111/j.1467$6494.2011 .00728 . x$

Vaish, A., Carpenter, M., \& Tomasello, M. (2011). Young children's responses to guilt displays. Developmental Psychology, 47(5), 1248-1262. https://doi.org/10.1037/a0024462

van der Wal, R. C., Karremans, J. C., \& Cillessen, A. H. (2017). Causes and consequences of children's 
forgiveness. Child Development Perspectives, 11(2), 97-101.

Wohl, M. J. A., \& Reeder, G. D. (2004). When Bad Deeds Are Forgiven: Judgments of Morality and Forgiveness for Intergroup Aggression. In Focus on aggression research (pp. 59-74). Nova Science Publishers.

Worthington Jr., E. L., Griffin, B. J., \& Provencher, C. (2018). Forgiveness. In Subjective well-being and life satisfaction (pp. 148-167). Routledge/Taylor \& Francis Group. 


\section{SUPPLEMENTARY INFORMATION}

Children are more forgiving of accidental harms across development

A. Additional Information $\quad 19$

A1. Additional Participant Information $\quad 19$

A2. Additional Coding Information 19

A3. Additional Information about Comprehension Questions 19

$\begin{array}{lr}\text { B. Location Information } & 20\end{array}$

C. Additional Analyses $\quad 21$

C1. Behavior Across Locations $\quad 21$

C2. Age Across Conditions $\quad 21$

C3. Condition Differences in Forgiveness Behavior 21

C4. No Effect of Recall on Forgiveness Behavior $\quad 25$

C5. No Effect of Age on Forgiveness in Baseline Condition $\quad 28$

D. Participants' Judgments of the Transgressor's Actions 29

$\begin{array}{ll}\text { E. Full Protocol \& Script } & 35\end{array}$ 


\section{A. Additional Information}

\section{A1. Additional Participant Information}

An additional 14 children were tested but excluded based on pre-specified criteria: parental intervention in the study $(n=1)$, failure to follow directions $(n=1)$, parent asked to stop $(n=1)$, neurodevelopmental disorders $(n=2)$, experimenter error $(n=7)$, language comprehension issues $(n=1)$, and previous participation in the task $(n=1)$.

For nine participants with incomplete date-of-birth information, exact age was imputed as their reported age plus six months (e.g. if a parent reported their child's age as 8 , their exact age was recorded as 8.5 years).

While individual demographic information was not collected for this study, information collected from subsequent studies by our team among these same locations, similar times of year, and age groups breaks down to roughly 57\% White, 13\% Asian, 13\% Other, 11\% Black or African American, and 6\% Hispanic, withy $92 \%$ of parents holding a bachelor's degree or higher.

\section{A2. Additional Coding Information}

All sessions in which parents provided consent for video recording (approximately $88 \%$ of our sample) were coded from both video and paper independently. Following exclusions, all of these participants were all included in the reliability analyses. A comparison of video and paper coding revealed high consistency, with a $93 \%$ match rate for the dependent variable of interest (number of sheets given back). In the small percentage of cases with coding conflict, a research assistant reviewed the live coding worksheet and video and then reconciled the discrepancy, which was then reviewed again and approved by the senior experimenter.

\section{A3. Additional Information about Comprehension Questions}

If a participant's response was not spontaneously correct, the experimenter repeated the correct information, then asked the comprehension question again. This process was repeated once more. If 
the participant failed at all three attempts, the researcher read the correct information to the child and moved on. We did not exclude on the basis of comprehension failures, in line with our a priori plan to not exclude such cases as children immediately receive the correct information before proceeding, but note that failure rates after three attempts on the two comprehension questions were quite low: $2 \%$ and $1 \%$, respectively.

\section{B. Location Information}

Participants were recruited and tested across six locations: in-lab on the Boston College campus, Artesani Park, the Boston Commons, the Boston Children's Museum, the Boston Zoo, and at the Discovery Museum (Table S1). We do not find evidence of location-based differences in condition assignment (Table S2).

Table S1: Breakdown of sample across locations.

\begin{tabular}{|c|c|c|c|c|c|c|}
\hline Location & $\begin{array}{c}\text { Discovery } \\
\text { Museum }\end{array}$ & $\begin{array}{c}\text { Artesani } \\
\text { Park }\end{array}$ & $\begin{array}{c}\text { Boston } \\
\text { Commons }\end{array}$ & $\begin{array}{c}\text { Boston Children's } \\
\text { Museum }\end{array}$ & In-Lab & Boston Zoo \\
\hline $\mathbf{N}$ & 147 & 10 & 79 & 7 & 2 & 12 \\
\hline
\end{tabular}

Table S2: Number of participants in each condition across locations.

\begin{tabular}{|c|c|c|c|c|c|c|}
\hline & $\begin{array}{c}\text { Discovery } \\
\text { Museum }\end{array}$ & $\begin{array}{c}\text { Artesani } \\
\text { Park }\end{array}$ & $\begin{array}{c}\text { Boston } \\
\text { Commons }\end{array}$ & $\begin{array}{c}\text { Boston Children's } \\
\text { Museum }\end{array}$ & In-Lab & Boston Zoo \\
\hline $\boldsymbol{A N R}$ & 26 & 3 & 15 & 2 & 0 & 4 \\
\hline $\boldsymbol{A R}$ & 30 & 2 & 17 & 0 & 1 & 3 \\
\hline $\boldsymbol{B}$ & 34 & 0 & 19 & 2 & 0 & 0 \\
\hline INR & 26 & 3 & 14 & 3 & 1 & 3 \\
\hline$I R$ & 31 & 2 & 14 & 0 & 0 & 2 \\
\hline
\end{tabular}




\section{Additional Analyses}

\section{C1. Behavior Across Locations}

We also do not find evidence for a significant effect of location on participants' behavior. We compared the final three models reported in the manuscript with identical models that also had location as a covariate. Model comparisons using Chi-square revealed no significant differences (all $p s>0.7$ ).

\section{C2. Age Across Conditions}

An ANOVA revealed no significant differences in age across conditions $[F(4,252)=0.35, p=0.84]$.

\section{C3. Condition Differences in Forgiveness Behavior}

We find no main effects of condition and no evidence of an interactive effect of age and condition on participants' forgiveness behavior (Table S3). Mean differences are visualized in Figure S1. A density plot of children's behavior by condition is in Figure S2. The age and condition interaction is visualized in Figure S3. 
Table S3: Effects and standard errors from a Poisson regression predicting number of sheets returned to the transgressor. Model 1 reports the main effects, Model 2 includes an exact age by condition interaction. Base levels for the model are the Baseline condition, and Female. Table also shows goodness of fit.

\begin{tabular}{|c|c|c|}
\hline & Model 1 & Model 2 \\
\hline \multirow[t]{2}{*}{ (Intercept) } & $1.08^{* * *}$ & $0.99^{* *}$ \\
\hline & $(0.17)$ & $(0.31)$ \\
\hline \multirow[t]{2}{*}{ Exact age } & 0.04 & 0.05 \\
\hline & $(0.02)$ & $(0.04)$ \\
\hline \multirow[t]{2}{*}{ AR vs. Baseline } & -0.07 & -0.34 \\
\hline & $(0.10)$ & $(0.48)$ \\
\hline \multirow[t]{2}{*}{ IR vs. Baseline } & -0.11 & 0.33 \\
\hline & $(0.10)$ & $(0.47)$ \\
\hline \multirow[t]{2}{*}{ ANR vs. Baseline } & -0.16 & -0.46 \\
\hline & $(0.10)$ & $(0.51)$ \\
\hline \multirow[t]{2}{*}{ INR vs. Baseline } & -0.12 & 0.50 \\
\hline & $(0.10)$ & $(0.48)$ \\
\hline \multirow[t]{2}{*}{ Male } & -0.07 & -0.08 \\
\hline & $(0.07)$ & $(0.07)$ \\
\hline \multirow[t]{2}{*}{ Exact age * AR } & & 0.03 \\
\hline & & $(0.06)$ \\
\hline \multirow[t]{2}{*}{ Exact age * IR } & & -0.06 \\
\hline & & $(0.06)$ \\
\hline \multirow[t]{2}{*}{ Exact age * ANR } & & 0.04 \\
\hline & & $(0.06)$ \\
\hline \multirow[t]{2}{*}{ Exact age * INR } & & -0.08 \\
\hline & & $(0.06)$ \\
\hline $\mathrm{AIC}$ & 994.15 & 996.85 \\
\hline $\mathrm{BIC}$ & 1019.00 & 1035.89 \\
\hline Log Likelihood & -490.08 & -487.42 \\
\hline Deviance & 229.71 & 224.41 \\
\hline Num. obs. & 257 & 257 \\
\hline
\end{tabular}


Statistical models

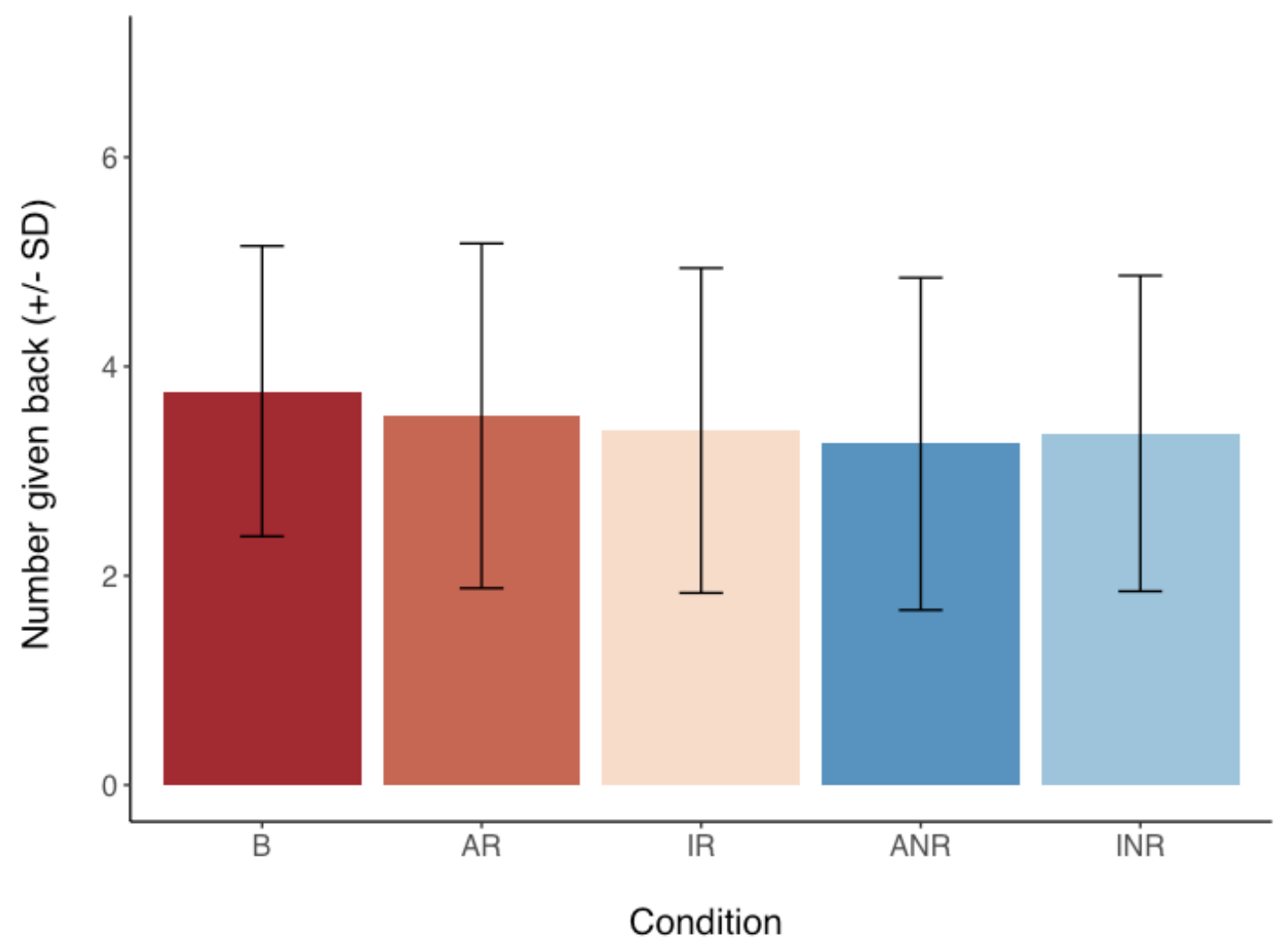

Figure S1: Mean number of sheets given back to the transgressor across conditions. Error bars represent standard deviations. $B=$ Baseline,$A R=$ Accidental $/$ Remorse, $I R=$ Intentional $/$ Remorse, ANR $=$ Accidental $/$ No Remorse, and INR = Intentional / No Remorse . 


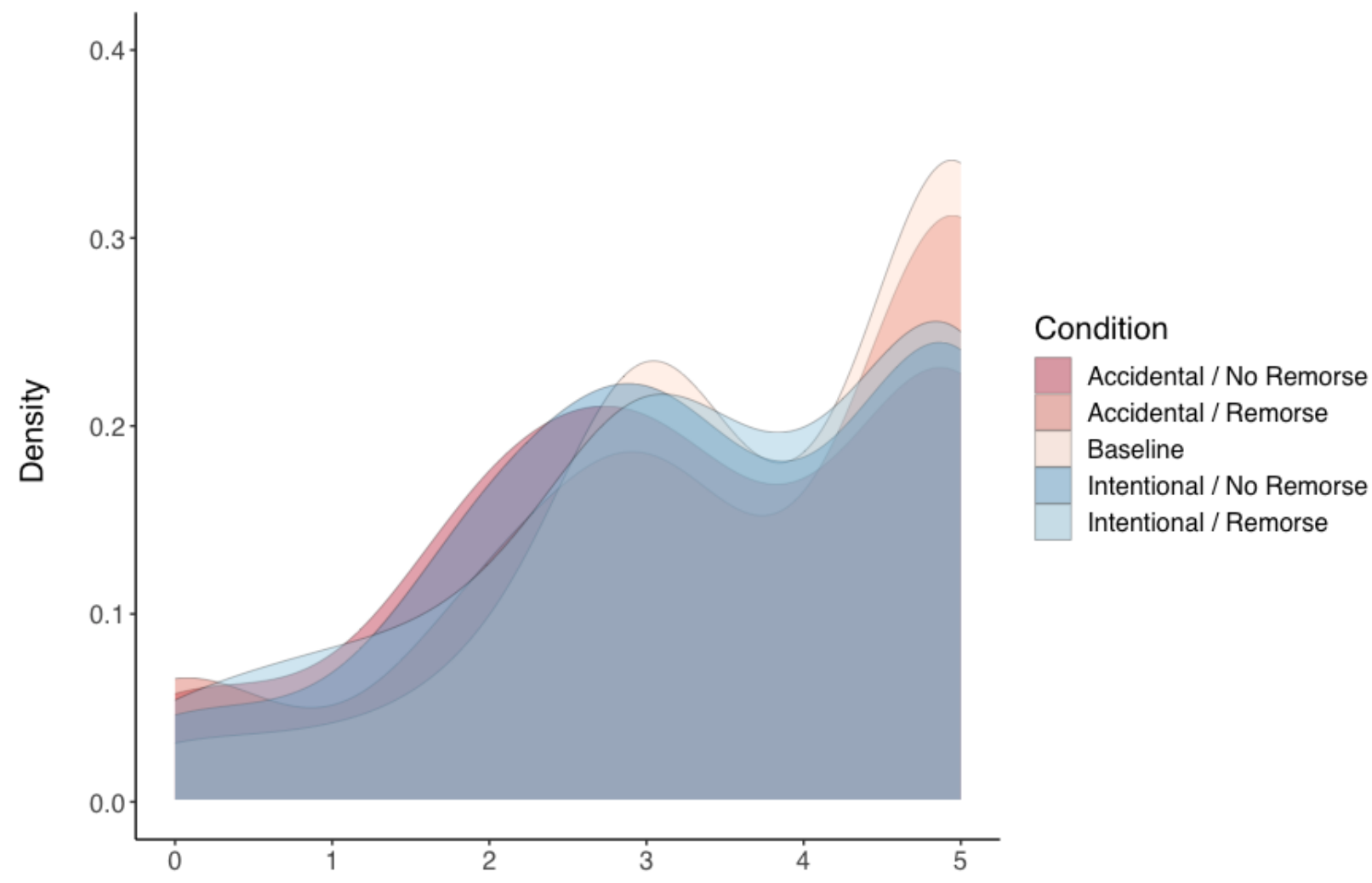

Number of Sheets Given Back

Figure S2: A density plot showing the number of sheets given back by condition. 


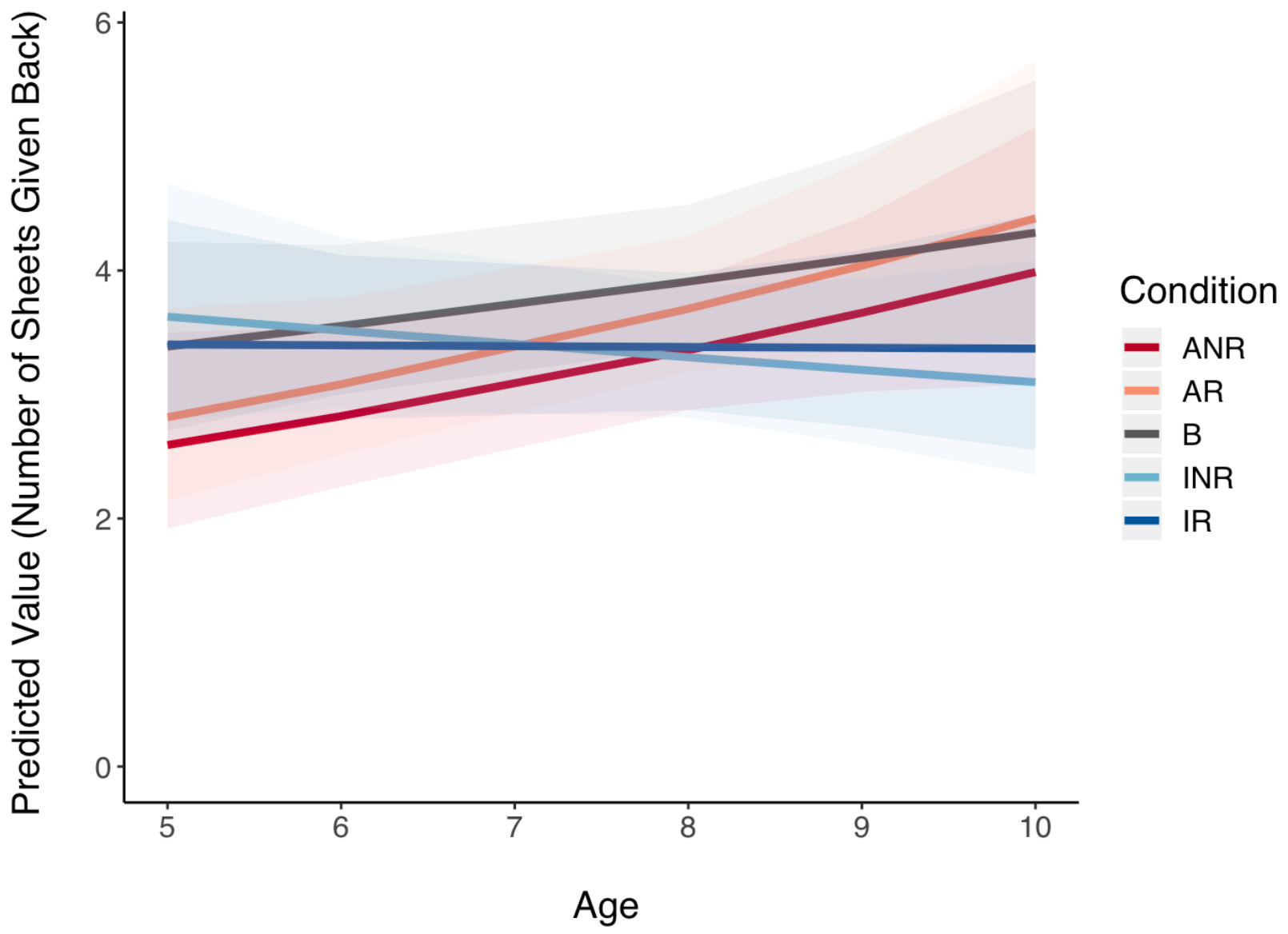

Figure S3: Predicted value of number of sheets given back by condition. The shaded ribbons represent $95 \%$ confidence intervals. $\mathrm{B}=$ Baseline, $\mathrm{AR}=$ Accidental $/$ Remorse, $\mathrm{IR}=$ Intentional $/$ Remorse, $\mathrm{ANR}=$ Accidental / No Remorse, and INR = Intentional / No Remorse.

\section{C4. No Effect of Recall on Forgiveness Behavior}

As a robustness check, we considered whether a participant's ability to accurately recall intent and remorse information influenced their forgiveness behavior. We built a new index variable to measure recall rate. Participants received a 1 for each recall question they were able to accurately answer. The majority of participants were able to recall both intent and remorse information $(72 \%, N=141)$ and received a score of 2 . A smaller portion of participants ( $24 \%, N=47)$ were able to accurately recall either remorse or intent information, and a smaller portion still $(4 \%, N=7)$ were unable to recall either.

We then incorporated this new variable into the three primary models reported in the main text. The primary conclusions do not change (see Table $\mathbf{S}_{4}$ ). Table $\mathrm{S}_{5}$ breaks down success and failures in the 
recall questions by condition. Note that "failures to recall" include both cases where children can't remember and cases where they give the wrong information. The way the variable was tracked by the experimenter lacks the granularity to allow us to differentiate between these two possibilities.

Table S4: Effects and standard errors from Poisson regressions predicting number of sheets returned to the transgressor. Model 1 reports the main effects, Model 2 includes the exact age by remorse interaction, and Model 3 includes an exact age by intent interaction. Table also shows goodness of fit.

\begin{tabular}{|c|c|c|c|}
\hline & $\begin{array}{l}\text { Main } \\
\text { effects }\end{array}$ & Remorse & Intent \\
\hline (Intercept) & $\begin{array}{l}0.83^{* * *} \\
(0.23)\end{array}$ & $\begin{array}{l}0.96^{* *} \\
(0.29)\end{array}$ & $\begin{array}{l}1.27^{* * *} \\
(0.29)\end{array}$ \\
\hline Exact Age & $\begin{array}{l}0.03 \\
(0.02)\end{array}$ & $\begin{array}{l}0.02 \\
(0.03)\end{array}$ & $\begin{array}{l}-0.02 \\
(0.03)\end{array}$ \\
\hline Accidental & $\begin{array}{l}0.01 \\
(0.08)\end{array}$ & & $\begin{array}{l}-0.90^{*} \\
(0.39)\end{array}$ \\
\hline Remorseful & $\begin{array}{l}0.02 \\
(0.08)\end{array}$ & $\begin{array}{l}-0.22 \\
(0.38)\end{array}$ & \\
\hline Male & $\begin{array}{l}-0.06 \\
(0.08)\end{array}$ & $\begin{array}{l}-0.06 \\
(0.08)\end{array}$ & $\begin{array}{l}-0.07 \\
(0.08)\end{array}$ \\
\hline Recall Sum & $\begin{array}{l}0.07 \\
(0.08)\end{array}$ & $\begin{array}{l}0.07 \\
(0.08)\end{array}$ & $\begin{array}{l}0.09 \\
(0.08)\end{array}$ \\
\hline Exact Age * Remorseful & & $\begin{array}{l}0.03 \\
(0.05)\end{array}$ & \\
\hline Exact Age * Accidental & & & $\begin{array}{l}0.11^{*} \\
(0.05)\end{array}$ \\
\hline AIC & 759.90 & $759 \cdot 53$ & 754.10 \\
\hline $\mathrm{BIC}$ & 779.54 & 779.17 & 773.74 \\
\hline Log Likelihood & -373.95 & -373.76 & -371.05 \\
\hline Deviance & 189.02 & 188.65 & 183.23 \\
\hline
\end{tabular}


Num. obs.

$\mathrm{p}<0.001,{ }^{* *} \mathrm{p}<0.01,{ }^{*} \mathrm{p}<0.05$

Statistical models 
Table S5: Recall rates for remorse and intent information, broken down by condition.

\begin{tabular}{|c|c|c|c|c|}
\hline Condition & ANR & AR & INR & $I R$ \\
\hline Recalled Remorse & 44 & 48 & 46 & 41 \\
\hline Did Not Recall Remorse & 6 & 4 & 4 & 5 \\
\hline Recalled Intent & 27 & 40 & 44 & 42 \\
\hline Did Not Recall Intent & 23 & 10 & 5 & 6 \\
\hline
\end{tabular}

\section{C5. No Effect of Age on Forgiveness in Baseline Condition}

We built a Poisson regression to look at the effect of age on forgiveness behavior in the Baseline condition (Table S6). We do not find evidence of age-related changes in forgiveness behavior.

Table S6: Effects and standard errors from Poisson regression predicting number of sheets returned to the transgressor by age, in just the Baseline condition. Table also shows goodness of fit.

\begin{tabular}{ll}
\hline & Baseline \\
\hline (Intercept) & $0.98^{* *}$ \\
& $(0.31)$ \\
Exact Age & 0.05 \\
& $(0.04)$ \\
\hline AIC & 208.35 \\
BIC & 212.37 \\
Log Likelihood & -102.18 \\
Deviance & 35.42 \\
Num. obs. & 55 \\
\hline *** $\quad$ p $<0.001,{ }^{* *} \mathrm{p}<0.01,{ }^{*} \mathrm{p}<0.05$
\end{tabular}


Statistical models

\section{Participants' Judgments of the Transgressor's Actions}

Following the decision, participants were then asked to judge the actions of the transgressor, first deciding if it was "okay or not okay" that the kid before them used their scratch sheets. Conditional upon this answer, the experimenter then followed up with a severity question. If the participant deemed the transgression as "not okay", the experimenter would ask; "Was it a little bad that they used your scratch sheets, pretty bad that they used your scratch sheets, or very, very bad that they used your scratch sheets?" If the participant deemed the transgression as "okay", the experimenter would ask; "Was it a little good that they used your scratch sheets, pretty good that they used your scratch sheets, or very, very good that they used your scratch sheets?"

To assess how participants' judgments varied across conditions, we first coded their responses from 1 to 6 , with 1 being "very, very good" and 6 being "very, very bad". Figure $\mathbf{S} 4$ shows participants' ratings of the badness of the transgressor's actions across conditions. In the Baseline and Accidental / Remorse conditions, participants judge the transgressor's actions more positively than in the other three conditions. Figure $\mathrm{S}_{5}$ shows how the proportion of participants deeming the transgressor's behavior as "not okay" by condition. Figure $\mathbf{S 6}$ shows the relationship between participant's judgments of the transgressors actions and the number of sheets they returned to the transgressor. 


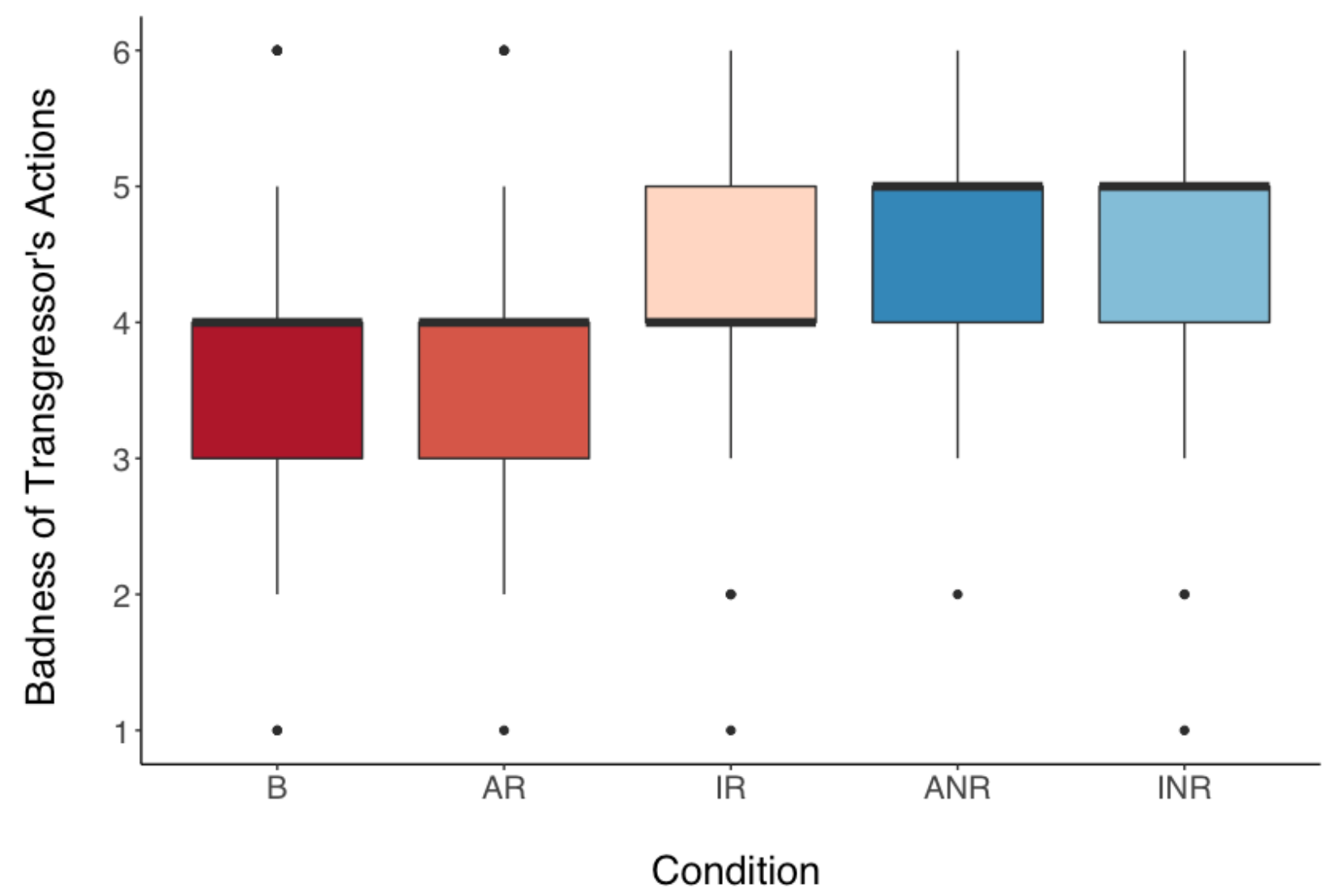

Figure $S_{4}$ : Boxplots representing participants' judgments of the transgressor's actions across conditions. $B=$ Baseline,$A R=$ Accidental $/$ Remorse,$I R=$ Intentional $/$ Remorse,$A N R=$ Accidental $/$ No Remorse, and INR = Intentional / No Remorse. Lower and upper box boundaries represent 25th and 75th percentiles, respectively. Bold lines represent medians. 


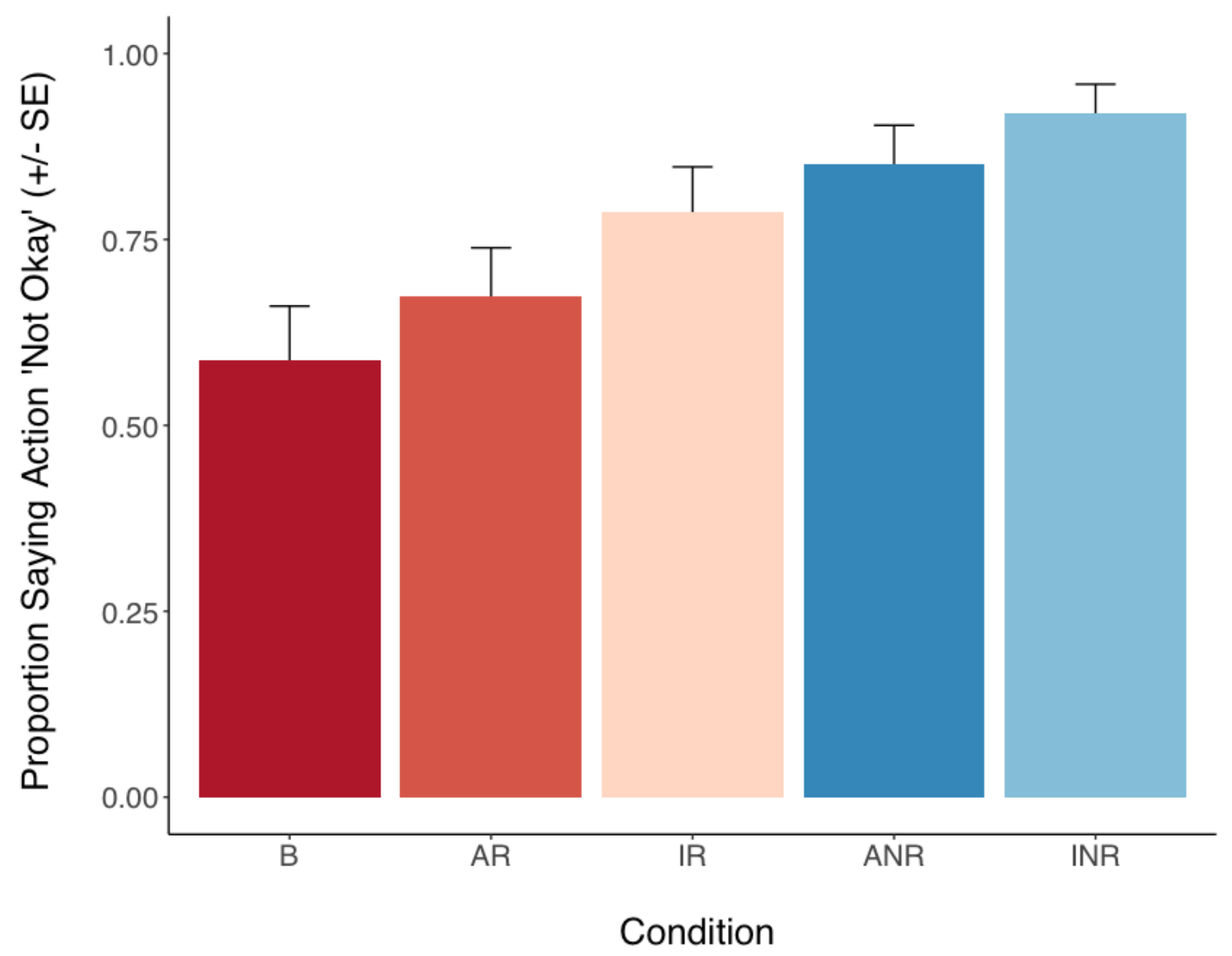

Figure S5: Proportion of participants saying the transgressor's action was "not okay" across conditions. $\mathrm{B}=$ Baseline, $\mathrm{AR}=$ Accidental $/$ Remorse, $\mathrm{IR}=$ Intentional $/$ Remorse, $\mathrm{ANR}=$ Accidental $/$ No Remorse and INR = Intentional / No Remorse. 


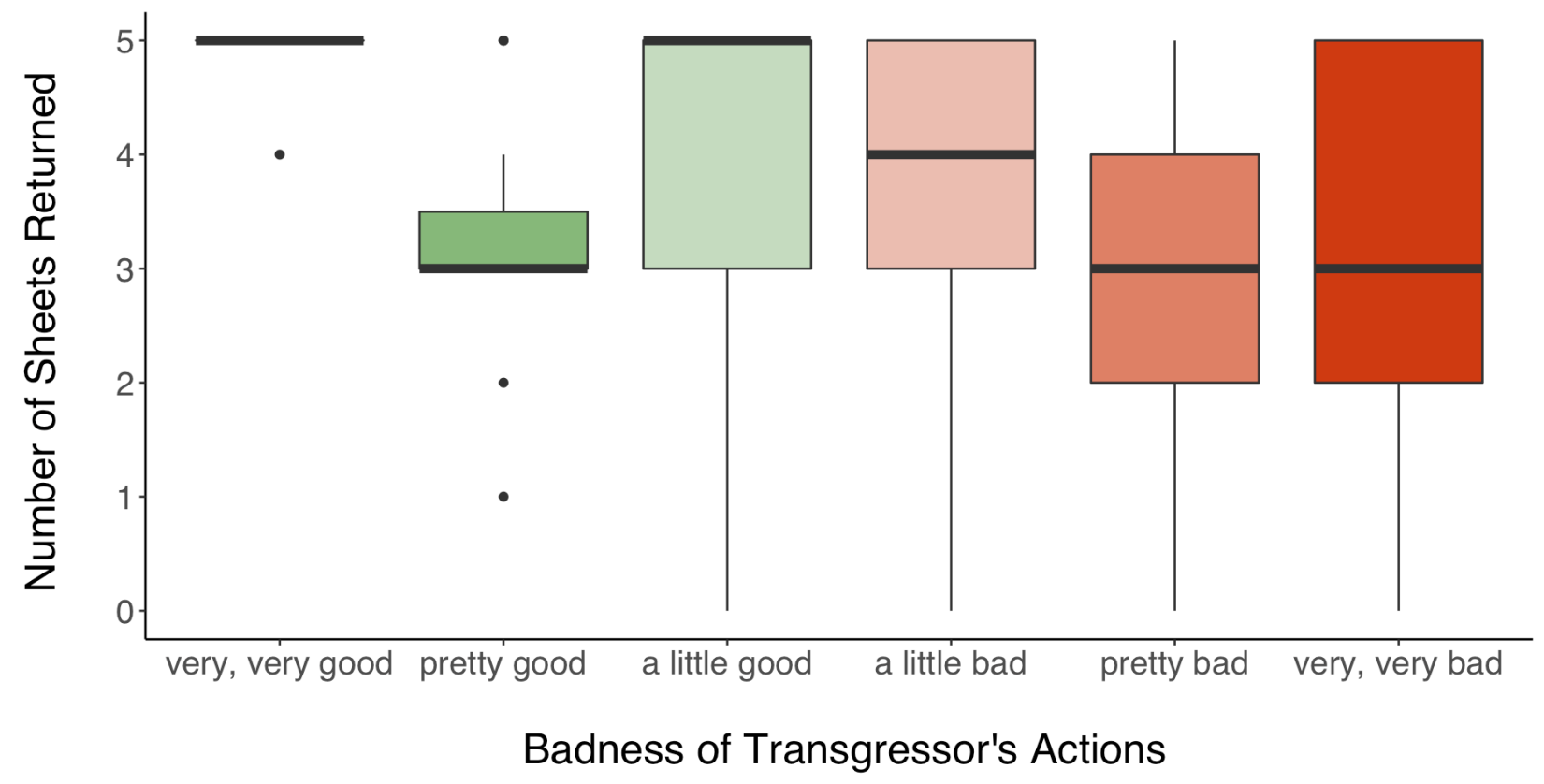

Figure S6: A boxplot visualizing the number of sheets returned by children's judgments of the transgressor's actions. Lower and upper box boundaries represent 25th and 75th percentiles, respectively. Bold lines represent medians. 
A linear regression (Table S7) comparing participants' judgments across conditions reveals that judgments of the transgressor's actions in the Intentional / Remorse, Accidental / No Remorse, and Intentional / No Remorse conditions are significantly different than in the Baseline condition. There is no difference between the Baseline condition and the Accidental / Remorse condition.

Table S7: Effects and standard errors from a linear regression predicting participants' ratings of the transgressor's actions across conditions. Base level for the model is the Baseline condition. Table also shows goodness of fit.

\begin{tabular}{lc}
\hline & Full sample \\
\hline (Intercept) & $3.72^{* * *}$ \\
& $(0.16)$ \\
Accidental / Remorse vs. Baseline & 0.16 \\
& $(0.22)$ \\
Intentional / Remorse vs. Baseline & $0.47^{*}$ \\
& $(0.22)$ \\
Accidental / No Remorse vs. Baseline & $0.84^{* * *}$ \\
Intentional / No Remorse vs. Baseline & $(0.22)$ \\
& $1.00^{* * *}$ \\
\hline $\mathrm{R}^{2}$ & $(0.22)$ \\
Adj. $\mathrm{R}^{2}$ & 0.11 \\
Num. obs. & 0.10 \\
RMSE & 240 \\
\hline$* * *$ \\
$\mathrm{p}<0.001,{ }^{* *} \mathrm{p}<0.01,{ }^{*} \mathrm{p}<0.05$ & 1.08 \\
\hline
\end{tabular}

Statistical models 
Running Title: Forgiveness in Children 


\section{E. Full Protocol \& Script}

"Hi, my name is [insert experimenter name]. What is your name? And how old are you? [Record]. I have a few games today, and in these games, you'll get the chance to take home some candy."

"But before we get started, I want to make sure that you know: you don't have to play these games if you don't want to. If you want to stop at any point, that's okay, you just let me know and we'll stop. You'll still get some candy."

"Do you want to play this game?" [Wait for assent]

"Here is a paper bag. I'll write your name on it. [Write name on bag]. Whatever candy you get in these games will go in this bag for you to take with you. I will give it to you at the very end."

"In this activity, you will get to make five rainbow scratch paper drawings! I will show you how it works using this tester." [Pull out tester strip.] "I can make a drawing by scratching on the sheet. Wherever I scratch, colors appear. [Draw a BIG star on the sheet to show how it works]. Isn't that cool?"

"Now you try." [Give child thirty seconds to draw on the sheet].

"Awesome! I'll put this in your bag for you to take home". [Put sheets into bag]

"Now I'm going to get five sheets for you to make drawings with!!" [Open box, pull out 5 completed drawing sheets.]

[Act disappointed \& surprised] "Oh no, it looks like someone before you already drew on them and you won't get to complete this activity. We don't have any more of these."

"Oh look, there's a note in here from my friend. [pull out note] It says..."

FIVE DIFFERENT CONDITIONS (Pre-assigned): 
(I/R) INTENTIONAL / REMORSE: "A kid that was here before you knew these were for you, but they drew on them anyway, on purpose. They are really sorry that they used the scratch sheets."

(I/NR) INTENTIONAL / NO REMORSE: "A kid that was here before you knew these were for you, but they drew on them anyway, on purpose. They are not sorry that they used the scratch sheets."

(A) ACCIDENTAL / REMORSE: "A kid that was here before you did not know these were for you, and they drew on them, accidentally. They are really sorry that they used the scratch sheets."

(R) ACCIDENTAL / NO REMORSE: "A kid that was here before you did not know these were for you, and they drew on them, accidentally. They are not sorry that they used the scratch sheets."

(B) BASELINE: "A kid that was here before drew on these scratch sheets."

"I know this is disappointing, but now it's up to you to decide what to do with the drawings. You have two choices. You can give as many as you want to the other kid who used them, or you can throw as many as you want away."

"Any drawings you want to give to them, you will put in this envelope [point to envelope]. Any drawings you want to throw away, you will throw into this trash can [point to trash can]."

"So, (C1) If you wanted to give a drawing to the other kid, where would you put it?" [record] "Yes, you would put it in the envelope."

[Comprehension coding: mark "SC" for spontaneously correct if they are correct on the first try. If they answer incorrectly, explain the instructions to them again, and ask the comprehension question again. If they answer correctly after the first explanation, mark "CWE " for correct with first explanation. If they still 
don't understand, explain the instructions again, and ask the question again. If they answer correctly after the second explanation, mark "CWE " for correct with second explanation. If they still don't get it, mark "I" for incorrect and move on." If still INCORRECT, make sure you actually give the child the answer before moving on]

\section{"And (C2) If you wanted to throw a drawing away, where would you put it?" [record]}

"Yes, you would throw it in the trash can"

"Ok, so now it's time to make your decision. I'm going to work on something for a minute. Let me know when you are finished and there no more scratch sheets on the table."

[Turn gaze away from child and fill out data sheet, or add in Notes to the worksheet; appear busy] [After 10 seconds, remind the participant to let you know when they're done.] "Are you all finished?" [If they're not finished, look away for another 10 seconds]

[Record how many pictures the participant put in the envelope and how many they did not.]

"Okay, thanks. Now, before we move on, I have a couple questions for you.".

\section{FOR BASELINE CONDITION:}

"When the kid before you used your scratch sheets, do you think what they did was OK or not OK?" [Record on worksheet]

[If Not OK]: "Was it a little bad that they used your scratch sheets, pretty bad that they used your scratch sheets, or very, very bad that they used your scratch sheets?" [Record on worksheet]

[If OK]: "Was it a little good that they used your scratch sheets, pretty good that they used your scratch sheets, or very, very good that they used your scratch sheets?" [Record on worksheet] 
"Ok, thanks for telling me that! Now we are all done with this activity. Let's move on to the next one."

\section{FOR ALL OTHER CONDITIONS:}

RECALL: "When the kid before you used your scratch sheets, do you remember if they did that on purpose or not on purpose?" [Record on worksheet]

RECALL: "And do you remember, were they sorry or not sorry?" [Record on worksheet]

"When the kid before you used your scratch sheets, do you think what they did was OK or not OK?" [Record on worksheet]

[If Not OK]: "Was it a little bad that they used your scratch sheets, pretty bad that they used your scratch sheets, or very, very bad that they used your scratch sheets?" [Record on worksheet]

[If OK]: "Was it a little good that they used your scratch sheets, pretty good that they used your scratch sheets, or very, very good that they used your scratch sheets?" [Record on worksheet]

"Ok, thanks for telling me that! Now we are all done with this activity." 